\title{
Targeting CXCR4 in AML and ALL
}

\author{
Daniel Cancilla, Michael P. Rettig and John F. DiPersio* \\ Division of Oncology, Department of Medicine, Washington University School of Medicine, St. Louis, MO, United States
}

The interaction of acute myeloid leukemia (AML) and acute lymphoblastic leukemia (ALL) blasts with the bone marrow microenvironment regulates self-renewal, growth signaling, as well as chemotherapy resistance. The chemokine receptor, CXC receptor 4 (CXCR4), with its ligand chemokine ligand 12 (CXCL12), plays a key role in the survival and migration of normal and malignant stem cells to the bone marrow. High expression of CXCR4 on AML and ALL blasts has been shown to be a predictor of poor prognosis for these diseases. Several small molecule inhibitors, short peptides, antibodies, and antibody drug conjugates have been developed for the purposes of more effective targeting and killing of malignant cells expressing CXCR4. In this review we will discuss recent results and strategies in targeting CXCR4 with these agents in patients with AML or ALL.

Keywords: AML, ALL, CXCR4, CXCL12, chemosensitization

\section{OPEN ACCESS}

Edited by:

Alan Wayne

Children's Hospital of Los Angeles,

United States

Reviewed by:

Yong-mi Kim,

Children's Hospital of Los Angeles,

United States

Sarah K. Tasian,

University of Pennsylvania

United States

${ }^{*}$ Correspondence:

John F. DiPersio

jdipersi@wustl.edu

Specialty section:

This article was submitted to

Hematologic Malignancies,

a section of the journal

Frontiers in Oncology

Received: 09 March 2020

Accepted: 29 July 2020

Published: 04 September 2020

Citation:

Cancilla D, Rettig MP and DiPersio JF

(2020) Targeting CXCR4 in AML and

ALL. Front. Oncol. 10:1672.

doi: 10.3389/fonc.2020.01672

\section{INTRODUCTION}

The chemokine receptor 4 (CXCR4) is a member of the G protein coupled receptor (GPCR) family of receptors and plays a role in numerous biological processes including fetal organ development, hematopoiesis, and immune system function. It is expressed on a wide range of hematopoietic cells including hematopoietic stem and progenitor cells (HSPCs) T cells, B cells, monocytes, macrophages, eosinophils, and neutrophils (1). The CXCR4 receptor was initially discovered in 1996 and studied in the context of human immunodeficiency virus-1 (HIV-1) as a co-receptor for viral entry into the cell (2). Further research revealed the role of CXCR4 in chemotaxis of white blood cells, retention of HSCs in the bone marrow, as well as involvement in several signaling pathways important for cellular proliferation, survival, and chemotactic migration [Figure 1A; for review see $(3,4)$ ]. The CXCR4 receptor interacts with the peptide signaling molecule stromal cell-derived factor 1 (SDF-1), also known as CXCL12, which is produced by bone marrow endothelial and stromal cells, including CXCL12-abundant reticular (CAR) cells (5-7). The migration of CXCR4 expressing cells along the CXCL12 gradient contributes to the chemotaxis of these cells and their retention within the bone marrow niche (7). The pro-survival effects of the CXCR4-CXCL12 interaction are thought to be mediated by activating mammalian target of rapamycin (mTOR) and downstream translation, while increased cellular proliferation is induced via activation of the signaling molecule extracellular signal related kinase (ERK-1/2) $(3,4)$.

CXCR4 is highly expressed in over 20 cancer types, ranging from hematological malignancies to solid tumors $(8,9)$. In leukemia, the receptor contributes to the retention of malignant cells in the bone marrow, which is thought to offer a protective environment to these cells in the presence of chemotherapeutic agents. This has been shown across multiple cancer types including acute myeloid leukemia (AML) and acute lymphoblastic leukemia (ALL) $(10,11)$. Therefore, CXCR4 might be an attractive molecular target for treating these malignancies. One predominant rationale for targeting the CXCL12/CXCR4 axis in AML and ALL is that its disruption will not only inhibit pro-survival signaling but also mobilize the leukemic cells from the protective bone marrow 


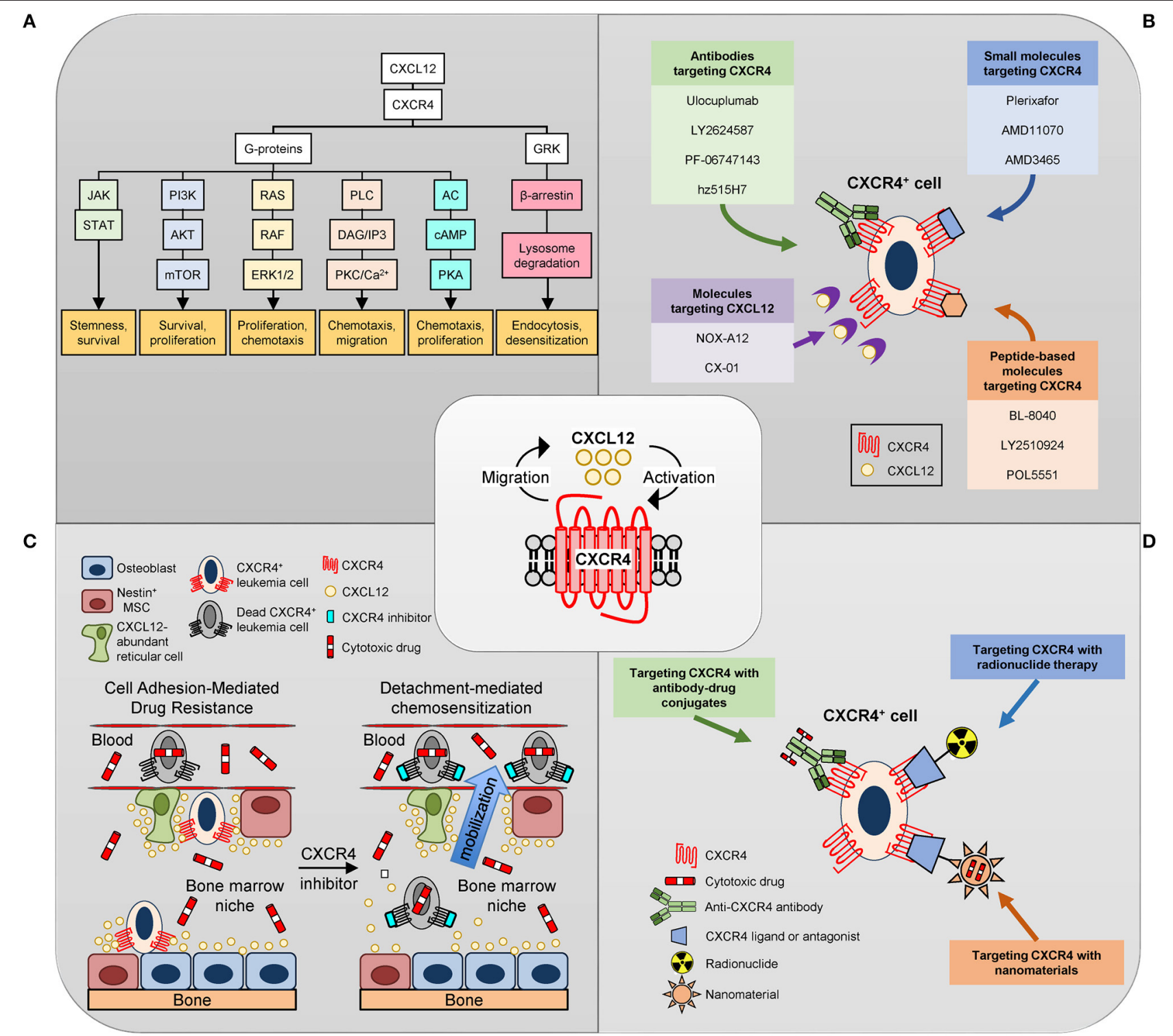

FIGURE 1 | Targeting CXCR4. (A) Overview of CXCL12/CXCR4 signal transduction pathways. CXCR4 is a seven-transmembrane spanning G-protein coupled receptor. Upon binding CXCL12, CXCR4 G-protein-mediated signaling leads to (a) activation of JAK/STAT signaling promoting stemness and survival, (b) activation of the phosphatidylinositol-3-kinase (PI3K)-Akt-mTOR pathway promoting cell survival and proliferation, (c) activation of Ras/Raf and mitogen-activated protein kinase (MAPK) signaling leading to phosphorylation of extracellular signal-regulated kinase (ERK) 1/2 which promotes survival and proliferation, (d) activation of phospholipase C (PLC) leading to diacylglycerol (DAG) and inositol triphosphate (IP3) production which induces $\mathrm{Ca}^{2+}$ efflux and protein kinase C (PKC) activation resulting in chemotaxis and migration, and (e) inhibition of adenylyl cyclase (AC), which reduces CAMP production and protein kinase $A$ activation leading to reduced cell proliferation and chemotaxis. CXCL12 also induces CXCR4 desensitization via uncoupling the receptor from G-proteins by GRK-dependent phosphorylation and subsequent $\beta$-arrestin-dependent endocytosis and lysosomal degradation. (B) Inhibitors of the CXCR4/CXCL12 axis. Drugs targeting CXCR4 can be divided into three general categories: (1) small molecules; (2) peptide-like molecules; and (3) antibodies. NOX-A12 disrupts the CXCR4/CXCL12 axis by binding and neutralizing CXCL12. (C) Schematic of CXCR4 inhibitor-mediated chemosensitization in leukemia. Osteoblasts, mesenchymal stem/stromal cells (MSC) and CXCL12-abundant reticular (CAR) cells in the bone marrow niche constitutively express CXCR12 leading to the recruitment and adhesion of CXCR4-expressing leukemia cells. These interactions provide a protective environment to the malignant cells in the presence of chemotherapeutic agents. Disruption of CXCR4-mediated adhesion of leukemia cells to the chemoprotective cells in the bone marrow niche via administration of CXCR4 inhibitors promotes mobilization and chemosensitization of leukemia cells. (D) Alternative approaches to target CXCR4-expressing cells. Antibodies to CXCR4 have been linked to cytotoxic drugs (antibody-drug conjugates; ADC) which induce cell death via DNA damage and/or microtubule disruption upon internalization. Several small molecule inhibitors and peptide-based antagonists of CXCR4 have been radiolabeled for positron emission tomography (PET) imaging or endoradiotherapy. Nanomaterials are small particles that serve as carriers for small-molecule drugs, proteins, and nucleic acids. Several nanomaterials targeting CXCR4 with the small molecule inhibitors, antibodies, or peptide-based antagonists discussed above have been developed. 
environment and out into the vasculature where they might be more susceptible to conventional chemotherapeutic agents (Figures 1B,C). This strategy is termed "chemosensitization" and has been tested in both animal models and human trials.

Recent studies have shown that in addition to being able to mobilize leukemic cells to the vasculature, some CXCR4 inhibitors have direct cytotoxic effects and can induce apoptosis in cells expressing the receptor. Because of these properties, there is growing interest in using CXCR4 inhibitors as part of an ablative chemotherapy regiment in the setting of hematopoietic cell transplant (HCT) or even as a monotherapy (12). Several small molecule inhibitors, short peptides, antibodies, and antibody drug conjugates (ADC) have been developed for the purposes of more effective targeting and killing of malignant cells expressing CXCR4 $(13,14)$. In this review we will discuss recent results and strategies in targeting CXCR4 with these agents in patients with AML or ALL.

\section{AML}

Acute myeloid leukemia (AML) is a clinically heterogeneous malignancy. A primary characteristic of this disease is the elevated level of immature myeloblasts in the marrow or peripheral blood. It is the leading cause of acute leukemia in the adult population and accounts for more deaths than any other leukemia (15). The current prognosis for patients with AML is poor, with a 5 -year survival rate of only $24 \%$ (16). Up to $40 \%$ of patients with AML fail to respond to initial therapy and remain refractory to all available treatment regimens from outset (17). In general, for relapsed or refractory patients with AML (rrAML), therapeutic choices are limited and the prognosis is exceptionally bleak, with a median overall survival of about 4 months (18). There is no established standard of care for patients with rrAML (18). Allogeneic hematopoietic cell transplant (HCT) is regarded as the only strategy with any possibility of a meaningful period of disease control but is limited by significant transplantrelated morbidity and mortality associated with high doses of chemotherapy and radiation therapy, which are needed to prepare patients for transplant, as well as graft-vs.-host disease (GvHD) (19).

\section{ALL}

Acute lymphoblastic leukemia is a hematologic malignancy characterized by impaired differentiation and proliferation of lymphoid progenitor cells. The age adjusted incidence of ALL is $\sim 1.7$ per 100,00 per year, with higher incidence in children than adults. ALL can be divided into B-cell ALL and T-cell ALL, with the former making up approximately $75 \%$ of cases and the latter making up $\sim 25 \%$ of cases (20). While treatments for ALL in children are very effective with cure rates around $90 \%$, treatments in adults are much less effective (21). Despite improved treatments, including the emergence of bispecific antibodies, chimeric antigen receptor therapy, and tyrosine kinase inhibitors for Philadelphia chromosome positive ALL, the overall adult survival rate is $<45 \%$ (22). Furthermore, in adults 60 years or older the 5 year survival rate is $<20 \%$ (23). Across all ages, relapse affects over $30 \%$ of patients. Relapsed or refractory ALL is associated with particularly poor outcomes with a reported $10 \% 3$ year survival rate in B-cell ALL. Outcomes are even worse in T-cell ALL (24). There is a clear need for additional therapies that can reduce the rate of relapse in these patients.

\section{CXCR4 EXPRESSION AND AML/ALL PROGNOSIS}

Studies have shown that increased expression of CXCR4 is associated with poor outcomes in patients with AML and Bcell ALL. This is potentially due to the role CXCR4 plays in keeping leukemic cells within the bone marrow as well as its roles in activating pathways that favor the survival, growth, and chemotherapy resistance of these malignant cells (1). Leukemic blasts with high CXCR4 expression in cases of AML was associated with higher rates of relapse and lower overall survival (25-35). Patients with a FMS-like tyrosine kinase3 internal tandem duplication (FLT3-ITD) or nucleophosmin mutation express significantly more CXCR4 than their wildtype counterparts $(27-29,31,32,36)$. However, these cytogenetic abnormalities do not solely account for the elevated CXCR4 expression in the disease as high CXCR4 expression is still a risk factor for prognosis in normal karyotype patients with AML $(29,30)$. Further, CXCR4 in French American British (FAB) AML-M4 and M5 subtypes is significantly increased relative to the other FAB and World Health Organization (WHO) AML subtypes $(27-29,31)$.

Fewer studies have evaluated CXCR4 expression in ALL. Like AML, high expression of CXCR4 is associated with worse overall survival in patients with B-cell ALL (37-41). Although no reports have linked high CXCR4 expression with a poor prognosis in T-cell ALL, it has been shown that T cell ALL interaction with CXCL12 is required for maintenance of disease in mouse models and that T ALL cells from both humans and mice show higher CXCR4 expression when compared to healthy cells $(42,43)$. There is also evidence that both AML and ALL cells upregulate CXCR4 during treatment with chemotherapy, suggesting that CXCR4 may play a role in chemotherapy resistance (44-46). Taken together, these data suggest that the CXCL12/CXCR4 axis influences outcomes and therapy responsiveness in AML and ALL.

\section{CXCR4 INHIBITION FOR CHEMOTHERAPY SENSITIZATION}

Given the body of evidence demonstrating that CXCR4 is not only a prognostic marker but also plays a role in leukemia progression, several strategies have emerged to potentially treat AML and ALL via targeting CXCR4. While the BM microenvironment supports proper development of hematopoietic stem and progenitor cells (HSPCs), it can also serve as a shelter for malignant cells by shielding them from cytotoxic chemotherapy (Figure 1C). It has been proposed that there is a sub-population of leukemic cells in AML and ALL 
know as leukemia initiating stem cells (LSC) that reside within the protective niche of the bone marrow (47-50). These cells are thought to be powerful contributors to drug resistance and relapse in these diseases. Chemosensitization aims to eliminate this LSC pool of cells by disrupting the interactions that keep them anchored within the bone marrow and exposing them to cytotoxic agents $(10,51,52)$. In addition to disrupting the anchorage of the LSC pool within the bone marrow niche, a secondary effect of targeting CXCR4 is to disrupt the survival and growth signaling mediated by this receptor. This is evidenced by studies showing elimination of cancer cells with CXCR4 inhibitor monotherapy $(53,54)$. Therefore, the combination of cell detachment and inhibition of pro-survival signaling may contribute to the efficacy of CXCR4 targeting agents.

Pathways responsible for the anchorage and survival of malignant cells, and therefore for their therapy resistance, were found to largely overlap with those described for normal HSPCs [reviewed in (55-61)]. Numerous studies have shown that CXCR4 antagonism, defined as the disruption of the interaction between CXCR4 and CXCL12, leads to mobilization of HSPCs into the blood circulation. These observations taken together provide the underlying rational for disruption of the CXCR4/CXCL12 axis in an attempt to sensitize the malignant cell populations within the bone marrow. Multiple pre-clinical studies in mouse models of AML $(12,62-66)$ or ALL (43, $45,67-71)$ have been reviewed elsewhere $(10,42,51,72)$ and provided proof of principle for the beneficial effects of combining CXCR4 inhibition with conventional chemotherapy compared to treatment with chemotherapy alone.

CXCR4 targeting drugs can be divided into four categories: (1) small molecule CXCR4 antagonists; (2) peptide-like CXCR4 antagonist; (3) antibodies to CXCR4; and (4) CXCL12 antagonists (Figure 1B). In general, both small molecule and peptide-like inhibitors of CXCR4 contain cationic regions capable of binding the predominantly anionic extracellular region of CXCR4. Crystal structures of CXCR4 complexed with a small molecule (isotiourea-1t; IT1t), peptide-like antagonist (CVX15) and a chemokine-like molecule (viral macrophage inflammatory protein 2) have been reported $(73,74)$. Not surprisingly, the peptide-like molecule mimicked the chemokine-like molecule in binding a major pocket in CXCR4 that is comprised of transmembrane (TM) domains three and seven of CXCR4 as well as more buried residues within the protein. In contrast, the IT1t small molecule bound a minor pocket between TM1-TM3 and TM7 in CXCR4. Subsequent site-directed mutational studies with different small molecule inhibitors have demonstrated that they can bind either the minor and/or major pockets of CXCR4 [for review see $(75,76)$ ]. Below we discuss the clinical results published to date with these four classes of CXCR4 targeting drugs in patients with AML and ALL (Table 1).

\section{Chemosensitization With Small Molecule CXCR4 Antagonist Plerixafor}

An extensive array of over 20 different chemical classes of small molecule CXCR4 antagonists have been developed since the original report of CXCR4 serving as a coreceptor for human immunodeficiency virus (HIV) 1 infection [for review (76)]. In 2008, the small molecule AMD3100 (plerixafor) was approved as an HSPC mobilizer (92-94). Clinically, plerixafor, in combination with granulocyte colony-stimulating factor (G$\mathrm{CSF}$ ), has proven effective for the mobilization of hematopoietic stem cells in patients with multiple myeloma (MM) and nonHodgkin's lymphoma (NHL) undergoing autologous stem cell transplantation (53). Further, plerixafor has been tested as a chemosensitizing agent in patients with AML or ALL. Below we briefly discuss these trials, where patients were treated with plerixafor alone or in combination with G-CSF in an attempt to enhance the efficacy of cytotoxic chemotherapy.

\section{Chemosensitization With Plerixafor Alone}

In the initial phase I/II study using a small molecule CXCR4 antagonist as a chemosensitizing agent (NCT00512252), 52 patients with relapsed or refractory AML (rrAML) were administered plerixafor followed by Mitoxantrone + Etoposide + Cytarabine (MEC) chemotherapy for 5 days (77). Like HSPCs, the mobilization of AML blasts by plerixafor was transient, and cell counts returned to baseline within $12 \mathrm{~h}$. Overall, $46 \%$ of the patients achieved a complete remission (CR) or complete remission with incomplete blood count recovery (CRi), which is a significantly higher rate compared to the historical response rate of $21 \%$ in similar patients receiving MEC chemotherapy alone (95). However, the median overall survival was only 8.2 months with a relapse-free survival of 9 months. Of note, the bolus injection of plerixafor in this trial induced significant upregulation of surface CXCR4 on AML blasts and increased their CXCL12-mediated chemotaxis. Since high CXCR4 expression is a marker of poor prognosis in AML, the plerixafor-mediated upregulation of CXCR4 on AML blasts might have reduced the efficacy of MEC chemotherapy in this trial.

In a small phase one trial of pediatric leukemia, 19 patients with relapsed or refractory leukemia (13 with AML, five with B-ALL) or myelodysplastic syndrome (MDS; $N=1$ ) were treated with plerixafor for 5 days followed $4 \mathrm{~h}$ later by high dose cytarabine and etoposide (NCT01319864). This treatment regimen was well-tolerated although there was only a modest $17 \%(3 / 18)$ clinical response in three patients with AML (78). No responses were observed in patients with ALL or MDS.

In subsequent trials, the efficacy of plerixafor chemosensitization was evaluated in newly diagnosed patients with AML treated with (1) a combination of cytarabine and daunorubicin (7 +3 regimen), (2) decitabine, or (3) clofarabine. In the first trial, 23 patients received cytarabine on days $1-7$, daunorubicin on days $1-3$, and plerixafor on days $2-7$ (NCT00990054). With this regimen, which was similar in toxicity to chemotherapy alone, $67 \%$ of patients (14/21) demonstrated complete remission (54). In the second trial (NCT01352650), 69 elderly patients received monthly cycles of a 10 day decitabine regimen with plerixafor administered $4 \mathrm{~h}$ prior to decitabine during alternating treatment cycles (79). Plerixafor failed to effectively sensitize the AML blasts to decitabine chemotherapy with patients exhibiting an overall response rate of $43 \%$ that 
TABLE 1 | Clinical trials targeting CXCR4 in combination with chemotherapy in AML and ALL.

\begin{tabular}{|c|c|c|c|c|c|c|}
\hline CXCR4 Inhibitor & Combined regimens & Disease & Phase & Age of enrollment & $\begin{array}{l}\text { ClinicalTrials.gov } \\
\text { identifier }\end{array}$ & References \\
\hline Plerixafor & $\begin{array}{l}\text { Mitoxantrone + Etoposide + } \\
\text { Cytarabine }\end{array}$ & AML & $1 / 2$ & $18-70$ & NCT00512252 & $(77)$ \\
\hline Plerixafor & Etoposide + Cytarabine & AML, B-ALL, MDS & 1 & 3-29 (Pediatric) & NCT01319864 & (78) \\
\hline Plerixafor & Daunorubicin + Cytarabine & AML & 1 & $18-70$ & NCT00990054 & (54) \\
\hline Plerixafor & Decitabine & AML & 1 & $60+$ & NCT01352650 & (79) \\
\hline Plerixafor & Clofarabine & AML & $1 / 2$ & $60+$ & NCT01160354 & - \\
\hline Plerixafor & $\begin{array}{l}\text { G-CSF + Mitoxantrone + Etoposide + } \\
\text { Cytarabine }\end{array}$ & AML & $1 / 2$ & $18-70$ & NCT00906945 & (80) \\
\hline Plerixafor & G-CSF + Daunorubicin + Cytarabine & AML & 1 & $18-65$ & $\begin{array}{l}\text { EudraCT number } \\
2011-000474-56\end{array}$ & $(81)$ \\
\hline Plerixafor & G-CSF + Sorafenib & AML & $1 / 2$ & $18+$ & NCT00943943 & $(82)$ \\
\hline Plerixafor & $\begin{array}{l}\text { G-CSF + Fludarabine, Idarubicin, and } \\
\text { Cytarabine }\end{array}$ & AML & $1 / 2$ & $18-65$ & NCT01435343 & (83) \\
\hline- & $\begin{array}{l}\text { G-CSF + Isofamide + Etoposide + } \\
\text { Dexamethasone }\end{array}$ & B-ALL, T-ALL & 1 & $18+$ & NCT01331590 & (84) \\
\hline BL-8040 & Cytarabine & AML & 1 & $18-75$ & NCT01838395 & (85) \\
\hline BL-8040 & Cytarabine & AML & 2 & $18-75$ & NCT02502968 & - \\
\hline BL8040 & Nelarabine & T-ALL & 2 & $18+$ & NCT02763384 & (86) \\
\hline LY2510924 & Idarubicin + Cytarabine & AML & 1 & 18-70 & NCT02652871 & $(87)$ \\
\hline Ulocuplumab & $\begin{array}{l}\text { Mitoxantrone + Etoposide + } \\
\text { Cytarabine }\end{array}$ & AML & 1 & $18+$ & NCT01120457 & (88) \\
\hline Ulocuplumab & Cytarabine & AML & 1 & $18+$ & NCT02305563 & - \\
\hline CX-01 & Idarubicin + Cytarabine & AML & 1 & $18-80$ & NCT02056782 & (89) \\
\hline CX-01 & Idarubicin + Cytarabine & AML & & $60+$ & NCT02873338 & (90) \\
\hline CX-01 & Azacitidine & AML & 1 & $18+$ & NCT02995655 & (91) \\
\hline
\end{tabular}

was similar to the $47 \%$ CR rate achieved in historical controls receiving decitabine alone (96). In the third trial (NCT01160354), plerixafor was administered to elderly patients $(N=22) 4-6 \mathrm{~h}$ prior to clofarabine for 5 consecutive days and no outcome data has been published to date.

\section{Chemosensitization With Plerixafor Plus G-CSF}

Since G-CSF acts synergistically when combined with plerixafor for HSPC mobilization $(97,98)$, it was proposed that this combination would more effectively disrupt AML blasts from the bone marrow microenvironment and render them susceptible to MEC chemotherapy. This hypothesis was further supported by previous studies indicating that "priming" with G-CSF prior to chemotherapy resulted in superior outcomes for patients receiving induction chemotherapy for AML (99). In the first chemosensitization trial with plerixafor, 20 patients with rAML were treated with G-CSF (days 1-8), plerixafor (days 3-8) and MEC chemotherapy (days 4-8) (80). This study was terminated after an interim analysis revealed that only 30\% (6 out of 20) of patients achieved a response with a median overall survival of 7.6 months (NCT00906945). In the second study, Heiblig et al. (81) tested a G-CSF (days 1-10) plus plerixafor (days 1-3 and 8-10) mobilization regimen in combination with daunorubicin (days 1-3), and cytarabine (days 1-3 and 8$10)$ in ten patients with AML after their first relapse from standard $(7+3)$ induction chemotherapy (EudraCT number
2011-000474-56). Encouragingly, eight of nine evaluable patients $(88 \%)$ achieved a response $(5-\mathrm{CR} ; 3-\mathrm{CRi})$ and seven proceeded to an allogeneic HSCT. This increased response rate compared to the first combination trial might have been due to the enrollment of younger patients with a more favorable risk stratification (majority of patients were favorable or intermediate risk). In the third study, sorafenib (days 1-28) was tested in combination with G-CSF and plerixafor (every other day from days 1-13) in 33 patients with rrAML with FLT3-ITD mutations (NCT00943943). A complete response rate of $28 \%$ was observed in 21 evaluable patients, including three patients refractory to previous FLT3 inhibitors (82). Finally, 57 patients with rrAML were administered both G-CSF and plerixafor in combination with fludarabine, idarubicin, and cytarabine (NCT01435343). Here, fludarabine, cytarabine, G-CSF, and plerixafor were all administered on days $1-4$, while idarubicin was only given on days 1-3 (83). The overall response rate of $49 \%$ (median overall and disease free survival of 9.9 and 13 months, respectively) was similar to a historical control group treated without plerixafor (100).

In contrast to AML, no reports to date describe ALL patients treated with plerixafor and G-CSF as part of a chemosensitization trial. However, 13 patients with rrALL (11 B-ALL; 2 T-ALL) were treated with G-CSF in combination with a salvage chemotherapy regimen consisting of isofamide with mesna, etoposide, and dexamethasone (NCT01331590). Three patients (2 B-ALL; 1 
T-ALL) achieved a complete remission (CR/CRi) for an overall response rate of $23 \%$ (84).

\section{Chemosensitization With Peptide-Based CXCR4 Antagonists}

BL-8040 is a 14 residue synthetic peptide that has a high affinity $(1 \mathrm{nM})$ and a slow dissociation rate $(>24 \mathrm{~h})$ from CXCR4 (101). Abraham et al. (102) demonstrated that BL-8040 directly caused AML cells to undergo apoptosis both in vitro and in vivo using various mouse models. In contrast, plerixafor alone did not elicit the same type of cytotoxic effects as BL-8040 (103). In a recently completed phase 2a trial (NCT01838395), 42 patients with rrAML were treated with BL-8040 monotherapy for 2 days followed by combined administration of BL-8040 and high dose cytarabine (HiDAC) for 5 days over one to two cycles (85). The response rate for all dosing levels was 29\% (12/42) with a median overall survival of 9.1 months that was $>6.1$ month median survival observed for a historical control group treated with HiDAC alone (104). In a separate trial (NCT02502968), patients with AML in first CR are treated with BL-8040 or placebo and HiDAC as part of a consolidation therapy approach. No data has been reported to date for this trial. Finally, in an ongoing trial involving patients with rrT-ALL, BL-8040 is being administered in combination with nelarabine (NCT02763384). Five of nine patients enrolled in the study have achieved a complete remission for an overall response rate of $56 \%$ (86).

LY2510924 is a small cyclic peptide containing non-natural amino acids that potently inhibits the binding of CXCL12 to CXCR4 $\left(\mathrm{IC}_{50}=0.08 \mathrm{nM}\right)$ and exhibits a long half-life $(9.16 \mathrm{~h})$ in humans (105). In a recently completed phase I study (NCT02652871), 11 patients with rrAML were treated with LY2510924 monotherapy for 7 days followed by combined administration of LY2510924 with idarubicin and cytarabine for 3 or 4 days (87). The overall response rate of $36 \%(4 / 11)$ was similar to a historical control group treated with idarubicin and cytarabine alone (106). One interesting observation from this trial was that, unlike plerixafor (77), LY2510924 administration was not associated with an upregulation of surface CXCR4 expression on the AML blasts (87). This lack of CXCR4 upregulation should prevent rapid re-homing of AML blasts to the protective BM microenvironment and promote the proapoptotic properties of CXCR4 blockade.

\section{Chemosensitization With Antibodies to CXCR4}

At least four monoclonal antibodies (mAbs) against CXCR4 (Ulocuplumab, LY2624587, PF-06747143, and hz515H7) have been tested in humans and many more antibodies, nanobodies, and other fragments targeting the CXCR4/CXCL12 axis are in pre-clinical development [for review see Bobkov et al. (107)]. Compared to small molecule inhibitors and peptidebased antagonists, mAbs exhibit longer blood half-lives (up to several weeks for IgG) and, depending on the IgG subclass, can possess Fc domain-mediated effector functions that facilitate the elimination of target-expressing cells via antibody-dependent cell-mediated toxicity (ADCC), antibodydependent cellular phagocytosis (ADCP), and/or complementdependent cytotoxicity.

Ulocuplumab, an IgG4 mAb that inhibits the binding of CXCL12 to CXCR4 and induces caspase-independent apoptosis on multiple cell lines and primary samples from patients with AML, chronic lymphocytic leukemia (CLL), and multiple myeloma (108-110). A phase one trial in 73 adults with rAML tested the antibody alone and in combination with MEC chemotherapy (NCT01120457). A 51\% overall CR/CRi rate was observed in the 43 patients who received ulocuplumab in combination with MEC chemotherapy (88). Four patients achieved a CR/CRi upon treatment with BMS-936564 alone indicating the antibody has some single-agent anti-leukemia activity (88). A phase $1 / 2$ study testing the antibody in combination with low dose cytarabine in newly diagnosed patients with AML was completed in June 2019 (NCT02305563) but no data has been published to date.

\section{Chemosensitization With Inhibitors of CXCL12}

CXCL12 antagonists have been designed for the purposes of disrupting the CXCR4/CXCL12 axis and sensitizing malignant cells to chemotherapy. CX-01 (dociparstat sodium; DSTAT) is a low molecular weight derivative of heparin that binds CXCL12 and is able to neutralize PF4, an inhibitor of megakaryopoiesis (111-113). In a small trial of 12 patients with AML (NCT02056782), CX-01 (days 1-7) was administered alongside cytarabine (days 1-7) and idarubicin (days 1-3) as part of induction and consolidation chemotherapy. The treatment regimen was safe and well-tolerated, with no CX-01-associated serious events (89). An overall response rate of $92 \%$ (11/12) was attained with all of the responders presenting with de novo AML. The $92 \%$ CR rate is higher than a $71 \%$ CR rate observed in a historical control cohort treated with cytarabine and idarubicin (114). A follow-up randomized, dose-response phase two study (NCT02873338) of the same regimen in 66 older patients $(>59$ years old) with AML recently reported a similar CR rate of $89 \%$ as well as significantly improved event free survival $(P=0.019)$ when compared to standard treatment alone (90). In a separate trial, hypomethylating agent (HMA)-refractory (received four or more cycles of HMA without response or disease progression on HMA therapy) patients with AML or MDS were treated with a 7 day continuous infusion of CX-01 and azacitidine in 28 day cycles (NCT02995655). The median overall response rate in 15 evaluable patients was $27 \%(4 / 15)$ with a median overall survival of 221 days (91). A randomized Phase three trial evaluating CX01 in combination with standard induction chemotherapy in newly diagnosed patients with AML is planned.

NOX-A12 is a pegylated L-enantiomeric RNA oligoribonucleotide (Spiegelmer) that binds and neutralizes CXCL12 thereby blocking its interaction with CXCR4 and CXCR7 $(115,116)$. In a phase one trial with healthy volunteers (NCT01194934), NOX-A12 was well-tolerated and mobilized CD34+ HSPCs in dose-dependent manner (116). Peak HSPC mobilization occurred within 1-4h of NOX-A12 administration 
and, in accordance with the plasma-half-life of $38 \mathrm{~h}$, remained elevated at 4 days after treatment. Although not tested in patients with AML and ALL to date, encouraging results have been obtained in clinical trials evaluating NOX-A12 in combination with bendamustine and rituximab for the treatment of relapsed or refractory patients with CLL (NCT01486797) (117) or bortezomib and dexamethasone in relapsed or refractory patients with multiple myeloma (NCT01521522) (118).

\section{Summary of Chemosensitization Studies Targeting CXCR4 in Patients With AML and ALL}

The initial clinical trials with plerixafor, BL-8040, Ly2510924, and ulocuplumab discussed above have demonstrated the feasibility and safety of combining CXCR4 inhibitors with chemotherapy in patients with AML or ALL and provided in vivo evidence for disruption of the CXCR4/CXCL12 signaling axis. However, results from these studies have been disappointing and, taken together, there is no obvious benefit over chemotherapy alone. This is highlighted by the fact that none of the regimens have entered into randomized phase three trials. The phase $2 \mathrm{~b}$ study assessing the safety and efficacy of BL-8040 vs. placebo as part of a cytarabine-based consolidation chemotherapy regimen in patients with AML is ongoing (NCT02502968) and the capability of BL-8040 to directly induce apoptosis in malignant but not normal cells may enhance the efficacy of chemosensitization. More favorable clinical responses have been observed following treatment of de novo AML patients with the CXCL12 antagonist CX-01 and chemotherapy. A randomized Phase three trial evaluating CX-01 in combination with standard induction chemotherapy in newly diagnosed patients with AML is planned. Since CXCR4 inhibitors haven't been tested in the upfront setting, it's unclear if the enhanced clinical activity observed with CX-01 is due to its different mechanism of action or the patient population under study.

\section{USING CXCR4 INHIBITORS IN MYELOABLATIVE CHEMOTHERAPY REGIMENS FOR HCT}

All of the clinical studies discussed thus far have combined disruption of the CXCR4/CXCL12 axis with drug and/or chemotherapy regimens that were of insufficient intensity to ablate the recipient's hematopoietic system. Hematopoietic stem cell transplantation (HSCT) allows for treatment with myeloablative therapy without concern for harming normal HSCs because of the hematopoietic rescue mediated by the transplanted untreated (i.e., non-chemotherapy-exposed) donor HSCs. HSCT thus provides a platform to combine CXCR4 antagonism with myeloablative chemotherapy. The rationale for this approach is that CXCR4 inhibition is thought to enhance donor HSPC engraftment during myeloablative conditioning by disrupting recipient HSPC retention within the bone marrow and sensitizing the recipient's normal HSPCs and leukemia stem cells to the cytotoxic conditioning chemotherapy. Below we discuss three trials where plerixafor was used as part of a myeloablative conditioning regimen for HCT in pediatric and adult patients with AML (Table 2). To our knowledge no patients with ALL have been treated with this approach to date.

In the first trial, plerixafor and G-CSF were included as part of a busulfan and fludarabine conditioning regimen for 45 adult patients (34 AML, seven MDS, and four CML) undergoing allogeneic HSCT (NCT00822770) (119). Although there was no observed difference in overall survival when compared to historical datasets of patients receiving only busulfan + fludarabine treatment, patients who received the mobilizing drugs showed increased rates of myeloid chimerism and lower rates of graft vs. host disease (GvHD) (119). In follow-up correlative studies, a negative correlation between survival and the percentage of AML blasts before and after conditioning was reported (122). The second trial included 12 adults with AML in first remission who underwent allogeneic HCT after receiving conditioning with plerixafor, busulfan, fludarabine, and 400 cGy total body irradiation (NCT01141543) (120). Plerixafor was administered $6 \mathrm{~h}$ before fludarabine and busulfan for up to 4 consecutive days (days -5 to -2 pre-HCT). Of the 12 patients enrolled, only two experienced disease relapse posttransplantation and six were alive at a median follow-up of 67 months (120). In the third trial, plerixafor was included as part of a myeloablative conditioning regimen for 12 pediatric patients with rrAML undergoing a second allogeneic HSCT (NCT01068301) (121). With a median duration of followup of 332 days, four of the 12 patients (33\%) were alive with two being disease free. Taken together, these studies demonstrate the safety and feasibility of adding plerixafor to a myeloablative conditioning regimen for allogeneic HSCT and further investigation is warranted.

\section{USING CXCR4 INHIBITORS TO ENHANCE DONOR ENGRAFTMENT AFTER HCT}

Plerixafor has also been tested for its ability to enhance donor engraftment and hematopoietic recovery after allogeneic HCT. Following myeloablative conditioning, post-transplant treatment with plerixafor led to increased recovery of donorderived cells in a murine transplant model (123). However, this effect was not observed by others following non-myeloablative conditioning of mice (124). In a phase I/II trial (NCT1280955), 30 patients with high-risk hematologic malignancies $(N=11$ patients with ALL; $N=15$ patients with AML/MDS) receiving myeloablative conditioning were treated with plerixafor every other day beginning day +2 until day +21 or until neutrophil recovery after allogeneic HCT (125). Plerixafor treatment had minor effects, with treated patients recovering absolute platelet counts $>20,000 / \mu \mathrm{L}$ only 1 day sooner than untreated patients. There was no difference in the time to neutrophil recovery between plerixafor-treated and untreated patients. This study demonstrated that plerixafor can be administered safely following myeloablative HCT but has minimal effects on enhancing hematopoietic recovery when given every other day at a dose of $240 \mu \mathrm{g} / \mathrm{kg}$. 
TABLE 2 | Clinical trials targeting CXCR4 in myeloablative chemotherapy regimens for HCT.

\begin{tabular}{|c|c|c|c|c|c|}
\hline CXCR4 Inhibitor & Combined regimens & Disease & Phase & ClinicalTrials.gov identifier & References \\
\hline Plerixafor & G-CSF + Busulfan + Fludarabine & AML, MDS, CML & $1 / 2$ & NCT00822770 & (119) \\
\hline Plerixafor & Busulfan + Fludarabine + TBI & AML & $1 / 2$ & NCT01141543 & (120) \\
\hline Plerixafor & Fludarabine + Thiotepa + Melphalan + rATG & AML & 1 & NCT01068301 & (121) \\
\hline
\end{tabular}

TBI, total body irradiation; rATG, rabbit antithymocyte globulin.

\section{TARGETING CXCR4 WITH ANTIBODY-DRUG CONJUGATES}

An antibody-drug conjugate (ADC) is a monoclonal antibody $(\mathrm{mAb})$ conjugated to a cytotoxic drug via a chemical linker (Figure 1D). Upon binding a target antigen on the surface of a cell, the ADC complex is internalized and degraded resulting in the release of the cytotoxic payload and cell death. Two publications have described ADCs targeting CXCR4 $(13,126)$. Costa et al. (126) screened multiple CXCR4-targeted ADCs and demonstrated efficient killing of multiple AML and ALL cell lines in vitro and non-small cell lung cancer cells in vivo. Their optimal ADC, ADC 713, was a low-affinity humanized IgG1 antibody with reduced Fc-mediator effector function. Tolerability and safety studies performed in a human CXCR4 knock-in mouse model (127) revealed significant decreases in the numbers of circulating neutrophils and monocytes 3 days after the third injection of ADC 713. Although the numbers of bone marrow lineage-negative/Sca-positive/Kit-positive (LSK) cells and HSPCs were unchanged, there was a significant decrease in granulocytemonocyte progenitors, suggesting some hematopoietic toxicity. Therefore, although CXCR4 may not be an ideal target for an ADC due to its widespread expression on normal HSPCs, mature leukocytes, kidney tubular epithelium and the adrenal gland (128), the majority of these cell populations are largely quiescent and should be relatively insensitive to auristatinmediated cell killing.

\section{TARGETING CXCR4 WITH RADIONUCLIDE THERAPY}

Several small molecule inhibitors and peptide-based antagonists of CXCR4 have been radiolabeled for positron emission tomography (PET) imaging [for review see $(129,130)]$. Three of these compounds: (1) ${ }^{64} \mathrm{Cu}$-AMD3100 (131), (2) ${ }^{68} \mathrm{Ga}$-NOTANFB (132), and (3) ${ }^{68}$ Ga-pentixafor (133) have been tested in humans. The rapid renal excretion and low non-specific background accumulation of the high affinity ${ }^{68} \mathrm{Ga}$-pentixafor compound has driven its clinical development as a diagnostic agent for CXCR4 in hematological and solid cancers as well as inflammatory conditions (129). A proof-of-concept study in 10 patients with AML demonstrated variable expression of CXCR4, with five of ten patients exhibiting ${ }^{68} \mathrm{Ga}$-pentixafor uptake that correlated well with AML infiltration as determined by magnetic resonance imaging (134). These data suggest that in vivo imaging of CXCR4 expression in patients with AML is feasible using ${ }^{68} \mathrm{Ga}$-pentixafor.
Pentixather is an analog of pentixafor that allows linkage of beta emitting radionuclides $\left({ }^{177} \mathrm{Lu} ;{ }^{90} \mathrm{Y}\right)$ that are routinely used in clinical practice for various cancer radiotherapies $(135,136)$. Habringer at al. (137) recently reported that endoradiotherapy with ${ }^{177}$ Lu-pentixather effectively targeted CXCR4+ tumor cells and significantly reduced leukemic burden in patient-derived and cell-line-based models of T-ALL and AML. Subsequent first-in-human studies of CXCR4-directed endoradiotherapy with ${ }^{177} \mathrm{Lu}$-pentixather or ${ }^{90} \mathrm{Y}$-pentixather in 22 patients with hematological malignancies (includes four patients with AML) have demonstrated the feasibility of this approach when combined with high-dose chemotherapy as part of a conditioning regimen for autologous or allogeneic stem cell transplantation $(137,138)$. Patients became anemic, neutropenic and thrombocytopenic after treatment with ${ }^{177} \mathrm{Lu}-$ pentixather or ${ }^{90} Y$-pentixather (138). This hematological toxicity was expected as there is a significant "cross-fire" effect from the radiolabeled pentixather that kills healthy hematopoietic HSPCs within the bone marrow upon targeting CXCR4-expressing cells. Although increasing the potential for off-target toxicity, this cross-fire irradiation may prove beneficial as it eliminates the need to target every single malignant cell and could disrupt and/or eradicate the tumor-supporting niche (137). Importantly, platelet and neutrophil engraftment after HSPC transplantation were not impaired by the CXCR4-directed endoradiotherapy. Therefore, the bone marrow niche was capable of supporting normal HSPCs after ${ }^{177} \mathrm{Lu}$-pentixather or ${ }^{90} \mathrm{Y}$-pentixather treatment. Finally, new scaffolds for delivering radiation to CXCR4 for imaging and endoradiotherapy have recently been developed from the small molecule CXCR4 inhibitor LY2510924 (139, 140).

\section{TARGETING CXCR4 WITH NANOMATERIALS}

Nanomaterials are small particles that serve as carriers for small-molecule drugs, proteins, and nucleic acids. Non-targeted liposomes containing conventional chemotherapeutic agents exhibit decreased toxicity compared to their corresponding free drugs and have been approved for use in patients with AML or ALL. Several pre-clinical studies using nanomaterials targeted to CXCR4 with the small molecule inhibitors, antibodies, or peptide-based antagonists discussed above have been reported [see Wang et al. (141) for review]. Although none of these pre-clinical studies have tested the efficacy of the CXCR4targeted nanomaterials against ALL cells to date, a couple of nanomaterial-based approaches have been tested against 
AML. First, Wang et al. (142) used CXCR4-targeted polymeric nanoparticles containing plerixafor to deliver siRNA against the transcription factor RUNX1 as well as inhibit the CXCR4CXCL12 axis in a mouse model of AML. Second, Diaz et al. (143) generated a CXCR4-targeted nanoparticle (via T22 peptide) containing ricin that was internalized and promoted AML killing in a CXCR4-dependent manner (143). In general, the combined capability to block the CXCR4/CXCL12 axis (via CXCR4 targeting moiety) while simultaneously delivering a drug payload (via nanomaterial) with a CXCR4-targeted nanomaterial could potentially enhance the efficacy and safety profile of therapeutics against AML and ALL. Like CXCR4-targeted ADCs and endoradiotherapy the main concern with CXCR4targeted nanomaterials is on-target, off-tumor toxicity to normal cell subsets.

\section{TARGETING CXCR4 IN COMBINATION WITH IMMUNE CHECKPOINT BLOCKADE}

BL-8040 is being tested in combination with the anti-PD-L1 antibody atezolizumab in intermediate and high-risk patients with AML who have achieved a CR following induction and consolidation therapy (NCT03154827). The rationale behind this combination is based on the observation across several studies that high CXCR4 expression is associated with decreased immune activation and diminished response to checkpoint inhibitor treatment $(144,145)$. The primary endpoint of this study is to assess whether the combination prolongs relapsefree survival. In addition to AML, the immune-mediated effects of BL-8040 are being examined in combination with PD-1/PDL1 immune checkpoint inhibitors in several clinical studies involving solid tumors (pancreatic, gastric, non-small cell lung cancer). These early-phase studies are being driven by pre-clinical data demonstrating that CXCR4 antagonism can enhance the efficacy of immune checkpoint treatment [see Gorbet et al. (146) for review].

\section{CONCLUSION AND FUTURE PERSPECTIVE}

The CXCR4 receptor plays a crucial role in the maintenance of leukemia through a variety of mechanisms, including prosurvival signaling and keeping leukemia cells sequestered in the protective bone marrow niche. This, coupled with its high level of expression on more than 20 different types of cancers, including $\mathrm{AML}$ and $\mathrm{ALL}$, make it an attractive target for treatment of these malignancies. To date, the predominant strategy used to target CXCR4 in patients with AML or ALL involves disruption of the CXCR4/CXCL12 axis in combination with cytotoxic chemotherapy.

Since the majority of these studies tested different chemotherapy regimens and enrolled small numbers of patients with different baseline characteristics, it's difficult to draw definitive conclusions about their relative effectiveness. In general, the results from these trials have been disappointing and only CX-01 is progressing toward a phase three trial.
Correlative studies from the chemosensitization trials discussed above have demonstrated that surface expression of functional CXCR4 often increases following inhibition of the CXCR4/CXCL12 axis. This upregulation of CXCR4 on the leukemic blasts may enhance pro-survival signaling and re-homing of the leukemic blasts to the protective $\mathrm{BM}$ niche thereby negating the efficacy of cytotoxic chemotherapy. One potential chemosensitization strategy that warrants further investigation is combining cytotoxic chemotherapy with a new class of CXCR4 inhibitors that are capable of biased antagonism of CXCR4. The peptide X4-2-6, which is derived from the second transmembrane helix and first extracellular loop of CXCR4, and small molecule CXCR4 inhibitor SEN071 have been shown in vitro to selectively inhibit the $G$ protein signaling dependent chemotaxis mediated via CXCR4 but not the beta arrestin recruitment and subsequent receptor endocytosis (147-149). Inhibition of the arrestin mediated endocytosis pathway is a proposed mechanism of tolerance to CXCR4 antagonists such as plerixafor (148). Agents such as X4-2-6 and SEN071 that inhibit G protein signaling of CXCR4 while sparing arrestin function may have the potential to significantly increase the efficacy of CXCR4 mediated chemosensitization.

Recently, Ramakrishnan et al. (150) demonstrated that CXCR4 alone provides sufficient signaling in the absence of CXCL12 ligation to promote the expansion and survival of murine AML cells in vivo. Therefore, if CXCR4 expression is maintained, disruption of the CXCR4/CXL12 axis alone might be insufficient to effectively sensitize leukemic cells to cytotoxic chemotherapy. If CXCL12 is indeed dispensable for the growth and persistence of leukemic blasts (or a subpopulation of LSCs) in patients with AML and ALL, more effective chemosensitization might only be attained following concomitant inhibition of both CXCL12 ligation (via a CXCR4/CXCL12 antagonist) and CXCR4 signaling. Several inhibitors of the RAS-RAF-MEKERK and PI3K-AKT-mTOR pro-survival signaling pathways downstream of CXCR4 exist and could be tested [for review see (151-154)]. Alternatively, inhibition of downstream CXCR4 signaling could be achieved via downregulation of the receptor. Some previously reported strategies to downregulate CXCR4 include treatment with (i) the small molecule bromodomain and extra-terminal domain-containing (BET) proteolysis-targeting chimera (PRTOAC) ARV-825 (155), (ii) lenalidomide or pomalidomide (156), and (iii) small interfering RNA [for review see Wang et al. (141)]. Additional pre-clinical studies combining cytotoxic chemotherapy with inhibition of CXCL12 ligation (via a CXCR4/CXCL12 inhibitor) and CXCR4 signaling or expression are warranted.

Finally, novel methods of mobilizing HSPCs continue to be studied with a number of pre-clinical compounds and/or regimens under investigation [for review see (157-159)]. Like healthy HSPCs, AML and ALL blasts express molecules other than CXCR4 that mediate adherence to BM stromal cells. Further, these molecules, such as VLA-4, LFA-1, E-selectin, and CD44, have been shown to provide anti-apoptotic and anti-proliferative effects and mediate chemotherapy resistance. Two phase three clinical trials testing the effectiveness of GMI-1271, an E-selectin inhibitor, to chemosensitize AML blasts in patients with de novo (NCT03701308) and rrAML 
(NCT03616470) are ongoing. Simultaneously targeting CXCR4 and these other adhesive interactions may increase the efficacy of chemotherapy sensitization.

\section{AUTHOR CONTRIBUTIONS}

DC, MR, and JD contributed to the writing of the manuscript. All authors contributed to the article and approved the submitted version.

\section{REFERENCES}

1. Teicher BA, Fricker SP. CXCL12 (SDF-1)/CXCR4 pathway in cancer. Clin Cancer Res. (2010) 16:2927-31. doi: 10.1158/1078-0432.CCR-09-2329

2. Feng Y, Broder CC, Kennedy PE, Berger EA. HIV-1 entry cofactor: functional cDNA cloning of a seven-transmembrane, G protein-coupled receptor. Science. (1996) 272:872-7. doi: 10.1126/science.272.5263.872

3. Heuninck J, Perpina Viciano C, Isbilir A, Caspar B, Capoferri D, Briddon SJ, et al. Context-dependent signaling of CXC chemokine receptor 4 and atypical chemokine receptor 3. Mol Pharmacol. (2019) 96:77893. doi: 10.1124/mol.118.115477

4. Mousavi A. CXCL12/CXCR4 signal transduction in diseases and its molecular approaches in targeted-therapy. Immunol Lett. (2019) 217:91115. doi: 10.1016/j.imlet.2019.11.007

5. Ding L, Morrison SJ. Haematopoietic stem cells and early lymphoid progenitors occupy distinct bone marrow niches. Nature. (2013) 495:2315. doi: 10.1038/nature11885

6. Greenbaum A, Hsu YM, Day RB, Schuettpelz LG, Christopher MJ, Borgerding JN, et al. CXCL12 in early mesenchymal progenitors is required for haematopoietic stem-cell maintenance. Nature. (2013) 495:22730. doi: 10.1038/nature11926

7. Sugiyama T, Kohara H, Noda M, Nagasawa T. Maintenance of the hematopoietic stem cell pool by CXCL12-CXCR4 chemokine signaling in bone marrow stromal cell niches. Immunity. (2006) 25:977-88. doi: 10.1016/j.immuni.2006.10.016

8. Chatterjee S, Behnam Azad B, Nimmagadda S. The intricate role of CXCR4 in cancer. Adv Cancer Res. (2014) 124:3182. doi: 10.1016/B978-0-12-411638-2.00002-1

9. Domanska UM, Kruizinga RC, Nagengast WB, Timmer-Bosscha H, Huls G, de Vries EG, et al. A review on CXCR4/CXCL12 axis in oncology: no place to hide. Eur J Cancer. (2013) 49:219-30. doi: 10.1016/j.ejca.2012.05.005

10. Peled A, Klein S, Beider K, Burger JA, Abraham M. Role of CXCL12 and CXCR4 in the pathogenesis of hematological malignancies. Cytokine. (2018) 109:11-16. doi: 10.1016/j.cyto.2018.02.020

11. Tesfai Y, Ford J, Carter KW, Firth MJ, O'Leary RA, Gottardo NG, et al. Interactions between acute lymphoblastic leukemia and bone marrow stromal cells influence response to therapy. Leuk Res. (2012) 36:299306. doi: 10.1016/j.leukres.2011.08.001

12. Cho BS, Zeng Z, Mu H, Wang Z, Konoplev S, McQueen T, et al. Antileukemia activity of the novel peptidic CXCR4 antagonist LY2510924 as monotherapy and in combination with chemotherapy. Blood. (2015) 126:222-32. doi: 10.1182/blood-2015-02-628677

13. Kularatne SA, Deshmukh V, Ma J, Tardif V, Lim RK, Pugh HM, et al. A CXCR4-targeted site-specific antibody-drug conjugate. Angew Chem Int Ed Engl. (2014) 53:11863-7. doi: 10.1002/anie.201408103

14. Schurch CM. Therapeutic antibodies for myeloid neoplasmscurrent developments and future directions. Front Oncol. (2018) 8:152. doi: $10.3389 /$ fonc. 2018.00152

15. Siegel RL, Miller KD, Jemal A. Cancer statistics, 2017. CA Cancer J Clin. (2017) 67:7-30. doi: 10.3322/caac.21387

16. Maynadie M, De Angelis R, Marcos-Gragera R, Visser O, Allemani C, Tereanu C, et al. Survival of European patients diagnosed with myeloid malignancies: a HAEMACARE study. Haematologica. (2013) 98:2308. doi: 10.3324/haematol.2012.064014

\section{FUNDING}

Research reported in this publication was supported by the National Cancer Institute of the National Institutes of Health under Award Number R50CA211466 (MR) and R35CA210084 (JD). The content was solely the responsibility of the authors and does not necessarily represent the official views of the National Institutes of Health.

17. Thol F, Schlenk RF, Heuser M, Ganser A. How I treat refractory and early relapsed acute myeloid leukemia. Blood. (2015) 126:31927. doi: 10.1182/blood-2014-10-551911

18. Stein EM, Tallman MS. Emerging therapeutic drugs for AML. Blood. (2016) 127:71-8. doi: 10.1182/blood-2015-07-604538

19. Ghimire S, Weber D, Mavin E, Wang XN, Dickinson AM, Holler E. Pathophysiology of GvHD and other HSCT-related major complications. Front Immunol. (2017) 8:79. doi: 10.3389/fimmu.2017.00079

20. Paul S, Kantarjian H, Jabbour EJ. Adult acute lymphoblastic leukemia. Mayo Clin Proc. (2016) 91:1645-66. doi: 10.1016/j.mayocp.2016.09.010

21. Pui CH, Yang JJ, Hunger SP, Pieters R, Schrappe M, Biondi A, et al. Childhood acute lymphoblastic leukemia: progress through collaboration. $J$ Clin Oncol. (2015) 33:2938-48. doi: 10.1200/JCO.2014.59.1636

22. Bassan R, Hoelzer D. Modern therapy of acute lymphoblastic leukemia. J Clin Oncol. (2011) 29:532-43. doi: 10.1200/JCO.2010.30.1382

23. Sive JI, Buck G, Fielding A, Lazarus HM, Litzow MR, Luger S, et al. Outcomes in older adults with acute lymphoblastic leukaemia (ALL): results from the international MRC UKALL XII/ECOG2993 trial. Br J Haematol. (2012) 157:463-71. doi: 10.1111/j.1365-2141.2012.09095.x

24. Bassan R, Bourquin J, DeAngelo DJ, Chiaretti S. New approaches to the management of adult acute lymphoblastic leukemia. J Clin Oncol. (2018) 36:3504-19. doi: 10.1200/JCO.2017.77.3648

25. Ahn JY, Seo K, Weinberg OK, Arber DA. The prognostic value of CXCR4 in acute myeloid leukemia. Appl Immunohistochem Mol Morphol. (2013) 21:79-84. doi: 10.1097/PAI.0b013e3182606f4d

26. Bae MH, Oh SH, Park CJ, Lee BR, Kim YJ, Cho YU, et al. VLA-4 and CXCR4 expression levels show contrasting prognostic impact (favorable and unfavorable, respectively) in acute myeloid leukemia. Ann Hematol. (2015) 94:1631-8. doi: 10.1007/s00277-015-2442-8

27. Cao T, Jiang N, Liao H, Shuai X, Su J, Zheng Q. The FLT3-ITD mutation and the expression of its downstream signaling intermediates STAT5 and Pim-1 are positively correlated with CXCR4 expression in patients with acute myeloid leukemia. Sci Rep. (2019) 9:12209. doi: 10.1038/s41598-019-48687-z

28. Cao T, Ye Y, Liao H, Shuai X, Jin Y, Su J, et al. Relationship between CXC chemokine receptor 4 expression and prognostic significance in acute myeloid leukemia. Medicine. (2019) 98:e15948. doi: 10.1097/MD.0000000000015948

29. Du W, Lu C, Zhu X, Hu D, Chen X, Li J, et al. Prognostic significance of CXCR4 expression in acute myeloid leukemia. Cancer Med. (2019) 8:6595603. doi: $10.1002 /$ cam 4.2535

30. Konoplev S, Rassidakis GZ, Estey E, Kantarjian H, Liakou CI, Huang $\mathrm{X}$, et al. Overexpression of CXCR4 predicts adverse overall and eventfree survival in patients with unmutated FLT3 acute myeloid leukemia with normal karyotype. Cancer. (2007) 109:1152-6. doi: 10.1002/cncr. 22510

31. Mannelli F, Cutini I, Gianfaldoni G, Bencini S, Scappini B, Pancani F, et al. CXCR4 expression accounts for clinical phenotype and outcome in acute myeloid leukemia. Cytometry B Clin Cytom. (2014) 86:3409. doi: 10.1002/cytob. 21156

32. Mohle R, Schittenhelm M, Failenschmid C, Bautz F, Kratz-Albers K, Serve H, et al. Functional response of leukaemic blasts to stromal cell-derived factor-1 correlates with preferential expression of the chemokine receptor CXCR4 in acute myelomonocytic and lymphoblastic leukaemia. Br J Haematol. (2000) 110:563-72. doi: 10.1046/j.1365-2141.2000.02157.x 
33. Rombouts EJ, Pavic B, Lowenberg B, Ploemacher RE. Relation between CXCR-4 expression, Flt3 mutations, and unfavorable prognosis of adult acute myeloid leukemia. Blood. (2004) 104:550-7. doi: 10.1182/blood-2004-02-0566

34. Spoo AC, Lubbert M, Wierda WG, Burger JA. CXCR4 is a prognostic marker in acute myelogenous leukemia. Blood. (2007) 109:786-91. doi: 10.1182/blood-2006-05-024844

35. Tavernier-Tardy E, Cornillon J, Campos L, Flandrin P, Duval A, Nadal N, et al. Prognostic value of CXCR4 and FAK expression in acute myelogenous leukemia. Leuk Res. (2009) 33:764-8. doi: 10.1016/j.leukres.2008.10.014

36. Abraham M, Pereg Y, Bulvik B, Klein S, Mishalian I, Wald H, et al. Single dose of the CXCR4 antagonist BL-8040 induces rapid mobilization for the collection of human CD34(+) cells in healthy volunteers. Clin Cancer Res. (2017) 23:6790-801. doi: 10.1158/1078-0432.CCR-16-2919

37. Crazzolara R, Kreczy A, Mann G, Heitger A, Eibl G, Fink FM, et al. High expression of the chemokine receptor CXCR4 predicts extramedullary organ infiltration in childhood acute lymphoblastic leukaemia. $\mathrm{Br}$ J Haematol. (2001) 115:545-53. doi: 10.1046/j.1365-2141.2001.03164.x

38. Ko SY, Park CJ, Park SH, Cho YU, Jang S, Seo EJ, et al. High CXCR4 and low VLA-4 expression predicts poor survival in adults with acute lymphoblastic leukemia. Leuk Res. (2014) 38:65-70. doi: 10.1016/j.leukres.2013.10.016

39. Konoplev S, Jorgensen JL, Thomas DA, Lin E, Burger J, Kantarjian $\mathrm{HM}$, et al. Phosphorylated CXCR4 is associated with poor survival in adults with B-acute lymphoblastic leukemia. Cancer. (2011) 117:468995. doi: $10.1002 / \mathrm{cncr} .26113$

40. Schneider P, Vasse M, Al Bayati A, Lenormand B, Vannier JP. Is high expression of the chemokine receptor CXCR-4 of predictive value for early relapse in childhood acute lymphoblastic leukaemia? Br J Haematol. (2002) 119:579-80. doi: 10.1046/j.1365-2141.2002.03835_6.x

41. van den Berk LC, van der Veer A, Willemse ME, Theeuwes MJ, Luijendijk MW, Tong WH, et al. Disturbed CXCR4/CXCL12 axis in paediatric precursor B-cell acute lymphoblastic leukaemia. Br J Haematol. (2014) 166:240-9. doi: 10.1111/bjh.12883

42. Chiarini F, Lonetti A, Evangelisti C, Buontempo F, Orsini E, Evangelisti C, et al. Advances in understanding the acute lymphoblastic leukemia bone marrow microenvironment: from biology to therapeutic targeting. Biochim Biophys Acta. (2016) 1863:449-63. doi: 10.1016/j.bbamcr.2015.08.015

43. Pitt LA, Tikhonova AN, Hu H, Trimarchi T, King B, Gong Y, et al. CXCL12-producing vascular endothelial niches control acute $\mathrm{T}$ cell leukemia maintenance. Cancer Cell. (2015) 27:755-68. doi: 10.1016/j.ccell.2015.05.002

44. Fei F, Stoddart S, Groffen J, Heisterkamp N. Activity of the aurora kinase inhibitor VX-680 against Bcr/Abl-positive acute lymphoblastic leukemias. Mol Cancer Ther. (2010) 9:1318-27. doi: 10.1158/1535-7163.MCT-10-0069

45. Sison EA, Magoon D, Li L, Annesley CE, Rau RE, Small D, et al. Plerixafor as a chemosensitizing agent in pediatric acute lymphoblastic leukemia: efficacy and potential mechanisms of resistance to CXCR4 inhibition. Oncotarget. (2014) 5:8947-58. doi: 10.18632/oncotarget.2407

46. Sison EA, McIntyre E, Magoon D, Brown P. Dynamic chemotherapyinduced upregulation of CXCR4 expression: a mechanism of therapeutic resistance in pediatric AML. Mol Cancer Res. (2013) 11:1004-16. doi: 10.1158/1541-7786.MCR-13-0114

47. Chopra M, Bohlander SK. The cell of origin and the leukemia stem cell in acute myeloid leukemia. Genes Chromosomes Cancer. (2019) 58:8508. doi: $10.1002 /$ gcc. 22805

48. Clarke MF. Clinical and therapeutic implications of cancer stem cells. $N$ Engl J Med. (2019) 380:2237-45. doi: 10.1056/NEJMra1804280

49. Senft D, Jeremias I. A rare subgroup of leukemia stem cells harbors relapseinducing potential in acute lymphoblastic leukemia. Exp Hematol. (2019) 69:1-10. doi: 10.1016/j.exphem.2018.09.006

50. Thomas D, Majeti R. Biology and relevance of human acute myeloid leukemia stem cells. Blood. (2017) 129:157785. doi: 10.1182/blood-2016-10-696054

51. Cho BS, Kim HJ, Konopleva M. Targeting the CXCL12/CXCR4 axis in acute myeloid leukemia: from bench to bedside. Korean J Intern Med. (2017) 32:248-57. doi: 10.3904/kjim.2016.244

52. Schroeder MA, Rettig MP, Lopez S, Christ S, Fiala M, Eades W, et al. Mobilization of allogeneic peripheral blood stem cell donors with intravenous plerixafor mobilizes a unique graft. Blood. (2017) 129:268092. doi: 10.1182/blood-2016-09-739722

53. Rettig MP, Ansstas G, DiPersio JF. Mobilization of hematopoietic stem and progenitor cells using inhibitors of CXCR4 and VLA-4. Leukemia. (2012) 26:34-53. doi: 10.1038/leu.2011.197

54. Uy GL, Avigan D, Cortes JE, Becker PS, Chen RW, Liesveld JL, et al. Safety and tolerability of plerixafor in combination with cytarabine and daunorubicin in patients with newly diagnosed acute myeloid leukemia- preliminary results from a phase I study. Blood. (2011) 118:82. doi: 10.1182/blood.V118.21.82.82

55. Cardoso BA. The bone marrow niche - the tumor microenvironment that ensures leukemia progression. Adv Exp Med Biol. (2020) 1219:25993. doi: 10.1007/978-3-030-34025-4_14

56. Duarte D, Hawkins ED, Lo Celso C. The interplay of leukemia cells and the bone marrow microenvironment. Blood. (2018) 131:150711. doi: 10.1182/blood-2017-12-784132

57. Gurska LM, Ames K, Gritsman K. Signaling pathways in leukemic stem cells. Adv Exp Med Biol. (2019) 1143:1-39. doi: 10.1007/978-981-13-7342-8_1

58. Levesque JP, Winkler IG. Cell adhesion molecules in normal and malignant hematopoiesis: from bench to bedside. Curr Stem Cell Rep. (2016) 2:35667. doi: 10.1007/s40778-016-0066-0

59. Mendez-Ferrer S, Bonnet D, Steensma DP, Hasserjian RP, Ghobrial IM, Gribben JG, et al. Bone marrow niches in haematological malignancies. Nat Rev Cancer. (2020) 20:285-98. doi: 10.1038/s41568-020-0245-2

60. Oh IH, Jeong SY, Kim JA. Normal and leukemic stem cell niche interactions. Curr Opin Hematol. (2019) 26:24957. doi: 10.1097/MOH.0000000000000508

61. Sanchez-Aguilera A, Mendez-Ferrer S. The hematopoietic stem-cell niche in health and leukemia. Cell Mol Life Sci. (2017) 74:57990. doi: 10.1007/s00018-016-2306-y

62. Han AR, Lee JY, Kim HJ, Min WS, Park G, Kim SH. A CXCR4 antagonist leads to tumor suppression by activation of immune cells in a leukemia-induced microenvironment. Oncol Rep. (2015) 34:28808. doi: 10.3892/or.2015.4297

63. Huang Y, Huang Z, An J, Xu Y. A novel dimeric CXCR4 antagonist synergizes with chemotherapy in acute myeloid leukaemia by mobilizing leukaemic cells from their associated bone marrow niches. Br J Haematol. (2019) 187:e11-5. doi: 10.1111/bjh.16127

64. Li X, Guo H, Duan H, Yang Y, Meng J, Liu J, et al. Improving chemotherapeutic efficiency in acute myeloid leukemia treatments by chemically synthesized peptide interfering with CXCR4/CXCL12 axis. Sci Rep. (2015) 5:16228. doi: 10.1038/srep16228

65. Nervi B, Ramirez P, Rettig MP, Uy GL, Holt MS, Ritchey JK, et al. Chemosensitization of acute myeloid leukemia (AML) following mobilization by the CXCR4 antagonist AMD3100. Blood. (2009) 113:6206-14. doi: 10.1182/blood-2008-06-162123

66. Zeng Z, Shi YX, Samudio IJ, Wang RY, Ling X, Frolova O, et al. Targeting the leukemia microenvironment by CXCR4 inhibition overcomes resistance to kinase inhibitors and chemotherapy in AML. Blood. (2009) 113:621524. doi: 10.1182/blood-2008-05-158311

67. Parameswaran R, Yu M, Lim M, Groffen J, Heisterkamp N. Combination of drug therapy in acute lymphoblastic leukemia with a CXCR4 antagonist. Leukemia. (2011) 25:1314-23. doi: 10.1038/leu.2011.76

68. Sison EA, Magoon D, Li L, Annesley CE, Romagnoli B, Douglas GJ, et al. POL5551, a novel and potent CXCR4 antagonist, enhances sensitivity to chemotherapy in pediatric ALL. Oncotarget. (2015) 6:3090218. doi: 10.18632/oncotarget.5094

69. Sison EA, Rau RE, McIntyre E, Li L, Small D, Brown P. MLLrearranged acute lymphoblastic leukaemia stem cell interactions with bone marrow stroma promote survival and therapeutic resistance that can be overcome with CXCR4 antagonism. Br J Haematol. (2013) 160:78597. doi: 10.1111/bjh.12205

70. Welschinger R, Liedtke F, Basnett J, Dela Pena A, Juarez JG, Bradstock $\mathrm{KF}$, et al. Plerixafor (AMD3100) induces prolonged mobilization of acute lymphoblastic leukemia cells and increases the proportion of cycling cells in the blood in mice. Exp Hematol. (2013) 41:293302.e1. doi: 10.1016/j.exphem.2012.11.004 
71. Yu M, Gang EJ, Parameswaran R, Stoddart S, Fei F, Schmidhuber S, et al. AMD3100 sensitizes acute lymphoblastic leukemia cells to chemotherapy in vivo. Blood Cancer J. (2011) 1:e14. doi: 10.1038/bcj.2011.13

72. Barbieri F, Bajetto A, Thellung S, Wurth R, Florio T. Drug design strategies focusing on the CXCR4/CXCR7/CXCL12 pathway in leukemia and lymphoma. Expert Opin Drug Discov. (2016) 11:1093-109. doi: 10.1080/17460441.2016.1233176

73. Qin L, Kufareva I, Holden LG, Wang C, Zheng Y, Zhao C, et al. Structural biology. Crystal structure of the chemokine receptor CXCR4 in complex with a viral chemokine. Science. (2015) 347:1117-22. doi: 10.1126/science.1261064

74. Wu B, Chien EY, Mol CD, Fenalti G, Liu W, Katritch V, et al. Structures of the CXCR4 chemokine GPCR with small-molecule and cyclic peptide antagonists. Science. (2010) 330:1066-71. doi: 10.1126/science.1194396

75. Adlere I, Caspar B, Arimont M, Dekkers S, Visser K, Stuijt J, et al. Modulators of CXCR4 and CXCR7/ACKR3 function. Mol Pharmacol. (2019) 96:73752. doi: 10.1124/mol.119.117663

76. Peng D, Cao B, Zhou YJ, Long YQ. The chemical diversity and structure-based evolution of non-peptide CXCR4 antagonists with diverse therapeutic potential. Eur J Med Chem. (2018) 149:148-69. doi: 10.1016/j.ejmech.2018.02.043

77. Uy GL, Rettig MP, Motabi IH, McFarland K, Trinkaus KM, Hladnik LM, et al. A phase 1/2 study of chemosensitization with the CXCR4 antagonist plerixafor in relapsed or refractory acute myeloid leukemia. Blood. (2012) 119:3917-24. doi: 10.1182/blood-2011-10-383406

78. Cooper TM, Sison EAR, Baker SD, Li L, Ahmed A, Trippett T, et al. A phase 1 study of the CXCR4 antagonist plerixafor in combination with highdose cytarabine and etoposide in children with relapsed or refractory acute leukemias or myelodysplastic syndrome: a pediatric oncology experimental therapeutics investigators' consortium study (POE 10-03). Pediatr Blood Cancer. (2017) 64:e26414. doi: 10.1002/pbc.26414

79. Roboz GJ, Ritchie EK, Dault Y, Lam L, Marshall DC, Cruz NM, et al. Phase I trial of plerixafor combined with decitabine in newly diagnosed older patients with acute myeloid leukemia. Haematologica. (2018) 103:130816. doi: 10.3324/haematol.2017.183418

80. Uy GL, Rettig MP, Stone RM, Konopleva MY, Andreeff M, McFarland K, et al. A phase $1 / 2$ study of chemosensitization with plerixafor plus G-CSF in relapsed or refractory acute myeloid leukemia. Blood Cancer J. (2017) 7:e542. doi: 10.1038/bcj.2017.21

81. Heiblig M, Elhamri M, Thomas X, Plesa A, Raffoux E, Hayette S. A phase 1 study of chemosensitization with plerixafor plus G-CSF in adults with relapsed acute myeloid leukemia. Leuk Res. (2018) 72:711. doi: 10.1016/j.leukres.2018.07.017

82. Andreeff M, Borthakur G, Zeng Z, Kelly MA, Wang R, McQueen TJ, et al. Mobilization and elimination of FLT3-ITD+ acute myelogenous leukemia (AML) stem/progenitor cells by plerixafor, G-CSF, and sorafenib: phase I trial results in relapsed/refractory AML patients. J Clin Oncol. (2014) 32:7033. doi: 10.1200/jco.2014.32.15_suppl.7033

83. Martinez-Cuadron D, Boluda B, Martinez P, Bergua J, RodriguezVeiga R, Esteve J, et al. A phase I-II study of plerixafor in combination with fludarabine, idarubicin, cytarabine, and G-CSF (PLERIFLAG regimen) for the treatment of patients with the first earlyrelapsed or refractory acute myeloid leukemia. Ann Hematol. (2018) 97:763-72. doi: 10.1007/s00277-018-3229-5

84. Uy GL, Hsu YM, Schmidt AP, Stock W, Fletcher TR, Trinkaus KM, et al. Targeting bone marrow lymphoid niches in acute lymphoblastic leukemia. Leuk Res. (2015) 39:1437-42. doi: 10.1016/j.leukres.2015. 09.020

85. Borthakur G, Tallman MS, Ofran Y, Foran J, Uy G, DiPersio J, et al. The CXCR4 inhibitor BL-8040 in combination with cytarabine results in a significantly extended overall survival of relapsed/refractory AML patients. EHA Libr. (2018) 215317:PS993. Available online at: https://library. ehaweb.org/eha/2018/stockholm/215317/gautam.borthakur.the.cxcr4. inhibitor.bl-8040.in.combination.with.cytarabine.html?f=ce_id $=1346^{\star}$ ot_ $\mathrm{id}=19045^{\star}$ media $=3$

86. Uy GL, Kadia TM, Stock W, Brammer JE, Bohana-Kashtan O, Vainstein A, et al. CXCR4 Inhibition with BL-8040 in combination with nelarabine in patients with relapsed or refractory $\mathrm{T}$-cell acute lymphoblastic leukemia/lymphoblastic lymphoma. Blood. (2019) 134:2630. doi: 10.1182/blood-2019-127121

87. Boddu P, Borthakur G, Koneru M, Huang X, Naqvi K, Wierda W, et al. Initial Report of a phase I study of LY2510924, idarubicin, and cytarabine in relapsed/refractory acute myeloid leukemia. Front Oncol. (2018) 8:369. doi: 10.3389/fonc.2018.00369

88. Becker P, Foran J, Altman J, Yacoub A, Castro J, Sabbatini P, et al. Targeting the CXCR4 pathway: safety, tolerability and clinical activity of ulocuplumab (BMS-936564), an anti-CXCR4 antibody, in relapsed/refractory acute myeloid leukemia. Blood. (2014) 124:386. doi: 10.1182/blood.V124.21.386.386

89. Kovacsovics TJ, Mims A, Salama ME, Pantin J, Rao N, Kosak KM, et al. Combination of the low anticoagulant heparin CX-01 with chemotherapy for the treatment of acute myeloid leukemia. Blood Adv. (2018) 2:3819. doi: 10.1182/bloodadvances.2017013391

90. Kovacsovics T, Levy MY, Cook RJ, Kolitz JE, Westervelt P, Donnellan WB, et al. A randomized phase II trial of CX-01 with standard therapy in elderly patients with acute myeloid leukemia (AML). J Clin Oncol. (2019) 37:7001. doi: 10.1200/JCO.2019.37.15_suppl.7001

91. Huselton E, Cashen AF, DiPersio JF, Jacoby M, Pusic I, Romee R, et al. Updated study results of CX-01, an inhibitor of CXCL12/CXCR4, and azacitidine for the treatment of hypomethylating agent refractory AML and MDS. Blood. (2019) 134:3915. doi: 10.1182/blood-2019-132065

92. De Clercq E. The AMD3100 story: the path to the discovery of a stem cell mobilizer (Mozobil). Biochem Pharmacol. (2009) 77:165564. doi: 10.1016/j.bcp.2008.12.014

93. De Clercq E. Recent advances on the use of the CXCR4 antagonist plerixafor (AMD3100, Mozobil) and potential of other CXCR4 antagonists as stem cell mobilizers. Pharmacol Ther. (2010) 128:509-18. doi: 10.1016/j.pharmthera.2010.08.009

94. Pusic I, DiPersio JF. Update on clinical experience with AMD3100, an SDF-1/CXCL12-CXCR4 inhibitor, in mobilization of hematopoietic stem and progenitor cells. Curr Opin Hematol. (2010) 17:319-26. doi: 10.1097/MOH.0b013e328338b7d5

95. Greenberg PL, Lee SJ, Advani R, Tallman MS, Sikic BI, Letendre L, et al. Mitoxantrone, etoposide, and cytarabine with or without valspodar in patients with relapsed or refractory acute myeloid leukemia and high-risk myelodysplastic syndrome: a phase III trial (E2995). J Clin Oncol. (2004) 22:1078-86. doi: 10.1200/JCO.2004.07.048

96. Blum W, Garzon R, Klisovic RB, Schwind S, Walker A, Geyer S, et al. Clinical response and miR-29b predictive significance in older AML patients treated with a 10-day schedule of decitabine. Proc Natl Acad Sci USA. (2010) 107:7473-8. doi: 10.1073/pnas.1002650107

97. DiPersio JF, Micallef IN, Stiff PJ, Bolwell BJ, Maziarz RT, Jacobsen E, et al. Phase III prospective randomized double-blind placebo-controlled trial of plerixafor plus granulocyte colony-stimulating factor compared with placebo plus granulocyte colony-stimulating factor for autologous stem-cell mobilization and transplantation for patients with non-hodgkin's lymphoma. J Clin Oncol. (2009) 27:4767-73. doi: 10.1200/JCO.2008. 20.7209

98. DiPersio JF, Stadtmauer EA, Nademanee A, Micallef IN, Stiff PJ, Kaufman JL, et al. Plerixafor and G-CSF versus placebo and GCSF to mobilize hematopoietic stem cells for autologous stem cell transplantation in patients with multiple myeloma. Blood. (2009) 113:57206. doi: 10.1182/blood-2008-08-174946

99. Lowenberg B, van Putten W, Theobald M, Gmur J, Verdonck L, Sonneveld $\mathrm{P}$, et al. Effect of priming with granulocyte colony-stimulating factor on the outcome of chemotherapy for acute myeloid leukemia. N Engl J Med. (2003) 349:743-52. doi: 10.1056/NEJMoa025406

100. Bergua JM, Montesinos P, Martinez-Cuadron D, Fernandez-Abellan P, Serrano J, Sayas MJ, et al. A prognostic model for survival after salvage treatment with FLAG-Ida +/-gemtuzumab-ozogamicine in adult patients with refractory/relapsed acute myeloid leukaemia. Br J Haematol. (2016) 174:700-10. doi: 10.1111/bjh.14107

101. Tamamura H, Fujisawa M, Hiramatsu K, Mizumoto M, Nakashima $\mathrm{H}$, Yamamoto N, et al. Identification of a CXCR4 antagonist, a T140 analog, as an anti-rheumatoid arthritis agent. FEBS Lett. (2004) 569:99104. doi: 10.1016/j.febslet.2004.05.056 
102. Abraham M, Klein S, Bulvik B, Wald H, Weiss ID, Olam D, et al. The CXCR4 inhibitor BL-8040 induces the apoptosis of AML blasts by downregulating ERK, BCL-2, MCL-1 and cyclin-D1 via altered miR-15a/16-1 expression. Leukemia. (2017) 31:2336-46. doi: 10.1038/leu.2017.82

103. Ricciardi MR, McQueen T, Chism D, Milella M, Estey E, Kaldjian E, et al. Quantitative single cell determination of ERK phosphorylation and regulation in relapsed and refractory primary acute myeloid leukemia. Leukemia. (2005) 19:1543-9. doi: 10.1038/sj.leu.2403859

104. Ravandi F, Ritchie EK, Sayar H, Lancet JE, Craig MD, Vey N, et al. Vosaroxin plus cytarabine versus placebo plus cytarabine in patients with first relapsed or refractory acute myeloid leukaemia (VALOR): a randomised, controlled, double-blind, multinational, phase 3 study. Lancet Oncol. (2015) 16:102536. doi: 10.1016/S1470-2045(15)00201-6

105. Peng SB, Zhang X, Paul D, Kays LM, Gough W, Stewart J, et al. Identification of LY2510924, a novel cyclic peptide CXCR4 antagonist that exhibits antitumor activities in solid tumor and breast cancer metastatic models. Mol Cancer Ther. (2015) 14:480-90. doi: 10.1158/1535-7163.MCT-14-0850

106. Short NJ, Kantarjian H, Ravandi F, Huang X, Xiao L, GarciaManero G, et al. A phase I/II randomized trial of clofarabine or fludarabine added to idarubicin and cytarabine for adults with relapsed or refractory acute myeloid leukemia. Leuk Lymphoma. (2018) 59:813-20. doi: 10.1080/10428194.2017.1349907

107. Bobkov V, Arimont M, Zarca A, De Groof TWM, van der Woning B, de Haard $\mathrm{H}$, et al. Antibodies targeting chemokine receptors CXCR4 and ACKR3. Mol Pharmacol. (2019) 96:753-64. doi: 10.1124/mol.119.116954

108. Kashyap MK, Kumar D, Jones H, Amaya-Chanaga CI, Choi MY, MeloCardenas J, et al. Ulocuplumab (BMS-936564 / MDX1338): a fully human anti-CXCR4 antibody induces cell death in chronic lymphocytic leukemia mediated through a reactive oxygen species-dependent pathway. Oncotarget. (2016) 7:2809-22. doi: 10.18632/oncotarget.6465

109. Kuhne MR, Mulvey T, Belanger B, Chen S, Pan C, Chong C, et al. BMS936564/MDX-1338: a fully human anti-CXCR4 antibody induces apoptosis in vitro and shows antitumor activity in vivo in hematologic malignancies. Clin Cancer Res. (2013) 19:357-66. doi: 10.1158/1078-0432.CCR-12-2333

110. Roccaro AM, Mishima Y, Sacco A, Moschetta M, Tai YT, Shi J, et al. CXCR4 regulates extra-medullary myeloma through epithelialmesenchymal-transition-like transcriptional activation. Cell Rep. (2015) 12:622-35. doi: 10.1016/j.celrep.2015.06.059

111. Joglekar MV, Quintana Diez PM, Marcus S, Qi R, Espinasse B, Wiesner $\mathrm{MR}$, et al. Disruption of $\mathrm{PF} 4 / \mathrm{H}$ multimolecular complex formation with a minimally anticoagulant heparin (ODSH). Thromb Haemost. (2012) 107:717-25. doi: 10.1160/TH11-11-0795

112. Krauel K, Hackbarth C, Furll B, Greinacher A. Heparininduced thrombocytopenia: in vitro studies on the interaction of dabigatran, rivaroxaban, and low-sulfated heparin, with platelet factor 4 and anti-PF4/heparin antibodies. Blood. (2012) 119:1248-55. doi: 10.1182/blood-2011-05-353391

113. Rao NV, Argyle B, Xu X, Reynolds PR, Walenga JM, Prechel M, et al. Low anticoagulant heparin targets multiple sites of inflammation, suppresses heparin-induced thrombocytopenia, and inhibits interaction of RAGE with its ligands. Am J Physiol Cell Physiol. (2010) 299:C97110. doi: 10.1152/ajpcell.00009.2010

114. Vogler WR, Velez-Garcia E, Weiner RS, Flaum MA, Bartolucci AA, Omura $\mathrm{GA}$, et al. A phase III trial comparing idarubicin and daunorubicin in combination with cytarabine in acute myelogenous leukemia: a southeastern cancer study group study. J Clin Oncol. (1992) 10:110311. doi: 10.1200/JCO.1992.10.7.1103

115. Roccaro AM, Sacco A, Purschke WG, Moschetta M, Buchner K, Maasch C, et al. SDF-1 inhibition targets the bone marrow niche for cancer therapy. Cell Rep. (2014) 9:118-28. doi: 10.1016/j.celrep.2014.08.042

116. Vater A, Sahlmann J, Kroger N, Zollner S, Lioznov M, Maasch C, et al. Hematopoietic stem and progenitor cell mobilization in mice and humans by a first-in-class mirror-image oligonucleotide inhibitor of CXCL12. Clin Pharmacol Ther. (2013) 94:150-7. doi: 10.1038/clpt.2013.58

117. Steurer M, Montillo M, Scarfo L, Mauro FR, Andel J, Wildner S, et al. Olaptesed pegol (NOX-A12) with bendamustine and rituximab: a phase IIa study in patients with relapsed/refractory chronic lymphocytic leukemia. Haematologica. (2019) 104:2053-60. doi: 10.3324/haematol.2018.205930
118. Ludwig H, Weisel K, Petrucci MT, Leleu X, Cafro AM, Garderet L, et al. Olaptesed pegol, an anti-CXCL12/SDF-1 spiegelmer, alone and with bortezomib-dexamethasone in relapsed/refractory multiple myeloma: a phase IIa study. Leukemia. (2017) 31:997-1000. doi: 10.1038/leu.2017.5

119. Konopleva M, Benton CB, Thall PF, Zeng Z, Shpall E, Ciurea S, et al. Leukemia cell mobilization with G-CSF plus plerixafor during busulfanfludarabine conditioning for allogeneic stem cell transplantation. Bone Marrow Transplant. (2015) 50:939-46. doi: 10.1038/bmt.2015.58

120. Michelis FV, Hedley DW, Malhotra S, Chow S, Loach D, Gupta V, et al. Mobilization of leukemic cells using plerixafor as part of a myeloablative preparative regimen for patients with acute myelogenous leukemia undergoing allografting: assessment of safety and tolerability. Biol Blood Marrow Transplant. (2019) 25:1158-63. doi: 10.1016/j.bbmt.2019.01.014

121. Srinivasan A, Panetta JC, Cross SJ, Pillai A, Triplett BM, Shook DR, et al. Phase I study of the safety and pharmacokinetics of plerixafor in children undergoing a second allogeneic hematopoietic stem cell transplantation for relapsed or refractory leukemia. Biol Blood Marrow Transplant. (2014) 20:1224-8. doi: 10.1016/j.bbmt.2014.04.020

122. Zeng Z, Liu W, Benton CB, Konoplev S, Lu H, Wang RY, et al. Proteomic profiling of signaling networks modulated by G-CSF/plerixafor/busulfanfludarabine conditioning in acute myeloid leukemia patients in remission or with active disease prior to allogeneic stem cell transplantation. Acta Haematol. (2019) 142:176-84. doi: 10.1159/000495456

123. Kang Y, Chen BJ, Deoliveira D, Mito J, Chao NJ. Selective enhancement of donor hematopoietic cell engraftment by the CXCR4 antagonist AMD3100 in a mouse transplantation model. PLoS ONE. (2010) 5:e11316. doi: 10.1371/journal.pone.0011316

124. Jiang Y, Ulyanova T, Papayannopoulou T. Is the post-transplantation treatment with AMD beneficial? Blood Cells Mol Dis. (2012) 49:2931. doi: 10.1016/j.bcmd.2012.03.005

125. Green MM, Chao N, Chhabra S, Corbet K, Gasparetto C, Horwitz A, et al. Plerixafor (a CXCR4 antagonist) following myeloablative allogeneic hematopoietic stem cell transplantation enhances hematopoietic recovery. $J$ Hematol Oncol. (2016) 9:71. doi: 10.1186/s13045-016-0301-2

126. Costa MJ, Kudaravalli J, Ma JT, Ho WH, Delaria K, Holz C, et al. Optimal design, anti-tumour efficacy and tolerability of anti-CXCR4 antibody drug conjugates. Sci Rep. (2019) 9:2443. doi: 10.1038/s41598-01938745-x

127. Costa MJ, Kudaravalli J, Liu WH, Stock J, Kong S, Liu SH. A mouse model for evaluation of efficacy and concomitant toxicity of anti-human CXCR4 therapeutics. PLoS ONE. (2018) 13:e0194688. doi: 10.1371/journal.pone.0194688

128. Fischer T, Nagel F, Jacobs S, Stumm R, Schulz S. Reassessment of CXCR4 chemokine receptor expression in human normal and neoplastic tissues using the novel rabbit monoclonal antibody UMB-2. PLoS ONE. (2008) 3:e4069. doi: 10.1371/journal.pone.0004069

129. Kircher M, Herhaus P, Schottelius M, Buck AK, Werner RA, Wester HJ, et al. CXCR4-directed theranostics in oncology and inflammation. Ann Nucl Med. (2018) 32:503-11. doi: 10.1007/s12149-018-1290-8

130. Liu N, Wan Q, Cheng Z, Chen Y. Radionuclide-labeled peptides for imaging and treatment of CXCR4- overexpressing malignant tumors. Curr Top Med Chem. (2019) 19:17-32. doi: 10.2174/15680266196661902010 94952

131. Weiss ID, Huff LM, Evbuomwan MO, Xu X, Dang HD, Velez DS, et al. Screening of cancer tissue arrays identifies CXCR4 on adrenocortical carcinoma: correlates with expression and quantification on metastases using (64)Cu-plerixafor PET. Oncotarget. (2017) 8:73387-406. doi: 10.18632/oncotarget.19945

132. Wang Z, Zhang M, Wang L, Wang S, Kang F, Li G, et al. Prospective study of (68)Ga-NOTA-NFB: radiation dosimetry in healthy volunteers and first application in glioma patients. Theranostics. (2015) 5:8829. doi: 10.7150/thno.12303

133. Wester HJ, Keller U, Schottelius M, Beer A, Philipp-Abbrederis K, Hoffmann F, et al. Disclosing the CXCR4 expression in lymphoproliferative diseases by targeted molecular imaging. Theranostics. (2015) 5:61830. doi: 10.7150/thno.11251

134. Herhaus P, Habringer S, Philipp-Abbrederis K, Vag T, Gerngross C, Schottelius $M$, et al. Targeted positron emission tomography imaging of 
CXCR4 expression in patients with acute myeloid leukemia. Haematologica. (2016) 101:932-40. doi: 10.3324/haematol.2016.142976

135. Herrmann K, Schottelius M, Lapa C, Osl T, Poschenrieder A, Hanscheid H, et al. First-in-human experience of CXCR4-directed endoradiotherapy with $177 \mathrm{Lu}-$ and 90Y-labeled pentixather in advanced-stage multiple myeloma with extensive intra- and extramedullary disease. J Nucl Med. (2016) 57:24851. doi: 10.2967/jnumed.115.167361

136. Schottelius M, Osl T, Poschenrieder A, Hoffmann F, Beykan S, Hanscheid $\mathrm{H}$, et al. [(177)Lu]pentixather: comprehensive preclinical characterization of a First CXCR4-directed endoradiotherapeutic agent. Theranostics. (2017) 7:2350-62. doi: 10.7150/thno.19119

137. Habringer S, Lapa C, Herhaus P, Schottelius M, Istvanffy R, Steiger K, et al. Dual targeting of acute leukemia and supporting niche by CXCR4-directed theranostics. Theranostics. (2018) 8:369-83. doi: 10.7150/thno.21397

138. Maurer S, Herhaus P, Lippenmeyer R, Hanscheid H, Kircher M, Schirbel A, et al. Side effects of CXC-chemokine receptor 4-directed endoradiotherapy with pentixather before hematopoietic stem cell transplantation. J Nucl Med. (2019) 60:1399-405. doi: 10.2967/jnumed.118.223420

139. Lau J, Kwon D, Rousseau E, Zhang Z, Zeisler J, Uribe CF, et al. $[(68) \mathrm{Ga}] \mathrm{Ga} /[(177) \mathrm{Lu}] \mathrm{Lu}-\mathrm{BL} 01$, a novel theranostic pair for targeting C-X-C chemokine receptor 4. Mol Pharm. (2019) 16:4688-95. doi: 10.1021/acs.molpharmaceut.9b00808

140. Suzuki K, Ui T, Nagano A, Hino A, Arano Y. C-terminal-modified LY2510924: a versatile scaffold for targeting C-X-C chemokine receptor type 4. Sci Rep. (2019) 9:15284. doi: 10.1038/s41598-019-51754-0

141. Wang Y, Xie Y, Oupicky D. Potential of CXCR4/CXCL12 chemokine axis in cancer drug delivery. Curr Pharmacol Rep. (2016) 2:1-10. doi: 10.1007/s40495-015-0044-8

142. Wang Y, Xie Y, Williams J, Hang Y, Richter L, Becker M, et al. Use of polymeric CXCR4 inhibitors as siRNA delivery vehicles for the treatment of acute myeloid leukemia. Cancer Gene Ther. (2019) 27:4555. doi: 10.1038/s41417-019-0095-9

143. Diaz R, Pallares V, Cano-Garrido O, Serna N, Sanchez-Garcia L, Falgas A, et al. Selective CXCR4(+) cancer cell targeting and potent antineoplastic effect by a nanostructured version of recombinant ricin. Small. (2018) 14: e1800665. doi: 10.1002/smll.201800665

144. Goltz D, Holmes EE, Gevensleben H, Sailer V, Dietrich J, Jung M, et al. CXCL12 promoter methylation and PD-L1 expression as prognostic biomarkers in prostate cancer patients. Oncotarget. (2016) 7:5330920. doi: 10.18632/oncotarget.10786

145. Jiang K, Li J, Zhang J, Wang L, Zhang Q, Ge J, et al. SDF-1/CXCR4 axis facilitates myeloid-derived suppressor cells accumulation in osteosarcoma microenvironment and blunts the response to anti-PD-1 therapy. Int Immunopharmacol. (2019) 75:105818. doi: 10.1016/j.intimp.2019.105818

146. Gorbet MJ, Ranjan A. Cancer immunotherapy with immunoadjuvants, nanoparticles, and checkpoint inhibitors: recent progress and challenges in treatment and tracking response to immunotherapy. Pharmacol Ther. (2019) 207:107456. doi: 10.1016/j.pharmthera.2019.107456

147. Castaldo C, Benicchi T, Otrocka M, Mori E, Pilli E, Ferruzzi P, et al. CXCR4 Antagonists: a screening strategy for identification of functionally selective ligands. J Biomol Screen. (2014) 19:859-69. doi: 10.1177/1087057114526283

148. Hitchinson B, Eby JM, Gao X, Guite-Vinet F, Ziarek JJ, Abdelkarim H, et al. Biased antagonism of CXCR4 avoids antagonist tolerance. Sci Signal. (2018) 11:eaat2214. doi: 10.1126/scisignal.aat2214

149. Tarasov SG, Gaponenko V, Howard OM, Chen Y, Oppenheim JJ, Dyba MA, et al. Structural plasticity of a transmembrane peptide allows self-assembly into biologically active nanoparticles. Proc Natl Acad Sci USA. (2011) 108:9798-803. doi: 10.1073/pnas.1014598108

150. Ramakrishnan R, Pena-Martinez P, Agarwal P, Rodriguez-Zabala M, Chapellier M, Hogberg C, et al. CXCR4 signaling has a CXCL12-independent essential role in murine MLL-AF9-driven acute myeloid leukemia. Cell Rep. (2020) 31:107684. doi: 10.1016/j.celrep.2020.107684

151. Kidger AM, Sipthorp J, Cook SJ. ERK1/2 inhibitors: new weapons to inhibit the RAS-regulated RAF-MEK1/2-ERK1/2 pathway. Pharmacol Ther. (2018) 187:45-60. doi: 10.1016/j.pharmthera.2018.02.007

152. Liu F, Yang X, Geng M, Huang M. Targeting ERK, an achilles' heel of the MAPK pathway, in cancer therapy. Acta Pharm Sin B. (2018) 8:55262. doi: 10.1016/j.apsb.2018.01.008

153. Nepstad I, Hatfield KJ, Gronningsaeter IS, Reikvam H. The PI3KAkt-mTOR signaling pathway in human acute myeloid leukemia (AML) cells. Int J Mol Sci. (2020) 21:2907. doi: 10.3390/ijms210 82907

154. Sanchez VE, Nichols C, Kim HN, Gang EJ, Kim YM. Targeting PI3K signaling in acute lymphoblastic leukemia. Int J Mol Sci. (2019) 20:412. doi: 10.3390/ijms20020412

155. Piya S, Mu H, Bhattacharya S, Lorenzi PL, Davis RE, McQueen T, et al. BETP degradation simultaneously targets acute myelogenous leukemia stem cells and the microenvironment. J Clin Invest. (2019) 129:187894. doi: 10.1172/JCI120654

156. Lopez-Millan B, Diaz de la Guardia R, Roca-Ho H, Anguita E, Islam A, Romero-Moya D, et al. IMiDs mobilize acute myeloid leukemia blasts to peripheral blood through downregulation of CXCR4 but fail to potentiate AraC/Idarubicin activity in preclinical models of non del5q/5qAML. Oncoimmunology. (2018) 7:e1477460. doi: 10.1080/2162402X.2018.14 77460

157. Domingues MJ, Nilsson SK, Cao B. New agents in HSC mobilization. Int J Hematol. (2017) 105:141-52. doi: 10.1007/s12185-016-2156-2

158. Karpova D, Rettig MP, DiPersio JF. Mobilized peripheral blood: an updated perspective. F1000Res. (2019) 8:2125. doi: 10.12688/f1000research.21129.1

159. Pelus LM, Broxmeyer HE. Peripheral blood stem cell mobilization; a look ahead. Curr Stem Cell Rep. (2018) 4:273-81. doi: 10.1007/s40778-0180141-9

Conflict of Interest: $\mathrm{MR}$ and JD have pending patent applications (PCT/US2017/059777; Integrin inhibitors and chemokine receptor agents, and PCT/US2017/059733 Integrin Antagonists) and report royalties received from them. JD is founder and advisor for Magenta Therapeutics, receives income, has equity ownership, and has received research funding from them. JD is an Advisory Board Member for Cellworks Group. BiolineRx has provided research funding for the work in the JD and MR laboratories.

The remaining author declares that the research was conducted in the absence of any commercial or financial relationships that could be construed as a potential conflict of interest.

Copyright (C) 2020 Cancilla, Rettig and DiPersio. This is an open-access article distributed under the terms of the Creative Commons Attribution License (CC BY). The use, distribution or reproduction in other forums is permitted, provided the original author(s) and the copyright owner(s) are credited and that the original publication in this journal is cited, in accordance with accepted academic practice. No use, distribution or reproduction is permitted which does not comply with these terms. 